\title{
10 health stories that mattered: July 7-11
}

- Nearly 1 in 8 deaths among Ontarians aged 25-34 was related to opioid use in 2010, states a study of 5935 opioid-related deaths published in Addiction. Opioid-related mortality increased 330\% between 1991 (127 deaths) and 2010 (550 deaths).

- The Federal Court has ruled that the Conservative government's refugee health care cuts violate charter rights. Justice Anne Mactavish denounced the cuts as "cruel and unusual" treatment, particularly toward the children of refugees. The government will appeal the decision.

- Food advertising needs to be regulated to "protect the health of Canadian children," Ontario researchers concluded in a study of foods marketed to children published in Obesity. Self-regulation has failed, half of advertised food is "nutritionally lacking" and food companies are making greater use of "spokescharacters" and other youth-oriented figures.

- Health Canada has given GlaxoSmithKline 30 days to create a plan to address problems at its vaccinemanufacturing plant in Ste. Foy, Quebec. The problems, details of which haven't been disclosed, don't pose an immediate threat to Canadians. The plant has a contract to produce $53 \%$ of Canada's seasonal flu vaccine for the 2014/15 flu season.

- There are many discrepancies among medicine labels and labelling guidelines in terms of things such as type size, justification and spacing, states a paper in the Canadian Pharmacists Journal. Difficult-to-read labels can lead to medication errors, particularly for older patients or those with vision impairment.

- Saskatchewan health workers must get the influenza vaccine or wear a mask while caring for patients during flu season this fall. Only half of health workers in the province voluntarily get the annual flu shot.

- A Liberal cabinet member in Quebec, Dr. Yves Bolduc, has been criticized for collecting $\$ 215000$ in bonuses for taking on 1500 patients while sitting in the opposition. There have been calls for Bolduc to repay the money and to resign. Bolduc says he will have to repay $\$ 40000-\$ 60000$ because he closed his practice before some patients had been under his care for a year, the timeframe required to receive a bonus.
- Preliminary results from a University of Manitoba study link contaminants from oil sands production to the declining health of residents in Fort Chipewyan, Alberta. According to the study, various illnesses, including cancer and respiratory, reproductive, circulatory and gastrointestinal diseases, are becoming more common among First Nations people who consume local wildlife containing high levels of contaminants from the oil sands.

- After 14 months of bargaining, Alberta Health Services is wrapping up negotiations on a new four-year contract with nurses that could see pay rates rise more than $7 \%$. Among other terms, the contract calls for "designated days of rest" for parttime nurses to prevent some from deliberately working overtime to earn higher pay, instead of taking full-time positions.

- Ontario launched a review of legislation that protects the secrecy of hospital investigations, amid concerns that the 2004 Quality of Care Information Protection Act has become a shield for health facilities, reports the Toronto Star.

CMAJ 2014. DOI:10.1503/cmaj.109-4852 